Article

\title{
Core Size and Interface Impact on the Exchange Bias of Cobalt/Cobalt Oxide Nanostructures
}

\author{
Maral Ghoshani ${ }^{1,2, *(D)}$, Morteza Mozaafari ${ }^{1}$, Peter S. Normile ${ }^{2}$, Jose A. De Toro ${ }^{2} \mathbb{D}$ and \\ Abdulrahman Al-Nabhani ${ }^{3}$
}

1 Department of Physics, Faculty of Science, University of Isfahan, Isfahan 81746-73441, Iran; mozafari@sci.ui.ac.ir

2 Instituto Regional de Investigación Científica Aplicada (IRICA), Departamento de Física Aplicada, Universidad de Castilla-La Mancha, 13071 Ciudad Real, Spain; peter.normile@uclm.es (P.S.N.); joseangel.toro@uclm.es (J.A.D.T.)

3 Electron Microscopy Unit, Pathology Department, College of Medicine and Health Science, Sultan Qaboos University, P.O. Box 36, Muscat 123, Oman; anabhani@squ.edu.om

* Correspondence: ghoshani.m@sci.ui.ac.ir; Tel.: +98-9133252351

Citation: Ghoshani, M.; Mozaafari, M.; Normile, P.S.; De Toro, J.A.; Al-Nabhani, A. Core Size and Interface Impact on the Exchange Bias of Cobalt/Cobalt Oxide

Nanostructures. Magnetochemistry 2021, 7, 40. https://doi.org/10.3390/ magnetochemistry7030040

Academic Editor: Andrea Caneschi

Received: 8 February 2021

Accepted: 9 March 2021

Published: 16 March 2021

Publisher's Note: MDPI stays neutral with regard to jurisdictional claims in published maps and institutional affiliations.

Copyright: (C) 2021 by the authors. Licensee MDPI, Basel, Switzerland. This article is an open access article distributed under the terms and conditions of the Creative Commons Attribution (CC BY) license (https:// creativecommons.org/licenses/by/ $4.0 /)$.

\begin{abstract}
Two series of Co/Co-oxide nanostructures have been synthesized by the co-precipitation method followed by different reduction and oxidation processes in an attempt to optimize their exchange bias (EB) properties. The samples are characterized by $\mathrm{X}$-ray diffraction, scanning and transmission electron microscopy, and SQUID (superconducting quantum interference device) magnetometry. The two series differ with respect to their average Co core grain sizes: in one (the $l$-series), the size is $\approx 100 \mathrm{~nm}$, and in the other (the $s$-series, obtained using lower synthesis temperatures than the $l$-series), it is $\approx 10 \mathrm{~nm}$. In the $l$-series, progressive oxidation yields an increase in the EB field together with a reduction in Co core size. In contrast, progressive oxidation in the s-series results in growth of the Co-oxide fraction at the expense of the Co core upon oxidation, which is accompanied by a decrease in the EB effect that is attributed to an ordering of the ferromagnetic-antiferromagnetic interface and therefore a reduction of uncompensated spins density. These results illustrate how the interface details become relevant only for small enough ferromagnetic cores.
\end{abstract}

Keywords: magnetic nanostructures; exchange bias; core/shell structure; cobalt oxide

\section{Introduction}

Magnetic nanoparticles (NPs) are attracting growing attention in both basic research and industry [1-6]. In particular, the study of magnetic nanostructures comprising two or more different magnetic materials has achieved considerable progress [1,2,7-10]. Advances in synthesis methods have allowed the fabrication of bi-magnetic nanostructures such as thin films and core/shell NPs, in which exchange coupling between the magnetic phases brings out novel or improved properties [2]. The properties of these heterostructures are different from those of each phase, leading to innovative applications [2,11-13]. Different combinations of exchange-coupled hard (with high $\mathrm{H}_{\mathrm{c}}$ ) and soft (providing high saturation magnetization) magnetic materials are used to design permanent magnets with enhanced energy products $[2,14]$.

There is much interest in the study of bi-magnetic systems with ferromagnetic (FM) antiferromagnetic (AFM) coupling, as it may provide a strong contribution to the effective magnetic anisotropy of the ferromagnet below the ordering (Néel) temperature of the AFM component. Possibly the most evident manifestation of such FM-AFM coupling is the appearance of a horizontal shift in a hysteresis loop measured after cooling the system in a saturating field from above the Néel temperature of its AFM component, i.e., a shift along the applied magnetic $(\mathrm{H})$ field axis, which is a parameter known as the exchange bias field $\left(\mathrm{H}_{\mathrm{E}}\right)$. The size of $\mathrm{H}_{\mathrm{E}}$ is often discussed in terms of the concept of uncompensated spins in the 
AFM component, which are located at its (or every) interface with the FM componentnamely, an imbalance in the number of "up" and "down" atomic magnetic moments in the AFM component, resulting in the development (upon cooling) of a contribution to the net magnetization of the system that is parallel to the saturated FM component and which, thus, introduces a unidirectional anisotropy along the cooling field direction $[1,2,7]$.

Most exchange bias (EB) applications are based on thin films, such as spin valve structures [15-17]; however, EB effects are prevalent in NP-based materials used, for example, in permanent magnets and certain biomedical technology $[1,2,7,18,19]$ (magnetic hyperthemia is one such biomedical application, where, recently, the associated toxicity of Co-containing NPs was suggested as a way to improve cancer therapeutic outcome [20]). Moreover, exchange coupling is an effective way to magnetically stabilize small FM particles against thermal fluctuations and, thus, it has been proposed as a strategy to design high-density magnetic recording media $[1,2,17,21-23]$. Magnetic proximity effects can be used to stabilize small Co NPs beyond $400 \mathrm{~K}$ by using the antiferromagnets $\mathrm{CoO}$ (which possesses a relatively high magnetic anisotropy) and $\mathrm{NiO}$ (a material of relatively high Néel temperature) as the shell and matrix materials that surround Co cores [23].

One of the key parameters governing EB is the FM/AFM volume ratio $[1,2,18]$, as the interfacial nature of the effects imposes a dependence of the EB field with the reciprocal of the FM volume [1]. Exchange bias has been extensively studied in thin films, where the FM and AFM layer thicknesses, and even the interface quality, can be readily controlled $[1,2,5,7,11,12,24]$. In bilayer films, the EB field has been shown to be proportional to the AFM thickness up to a critical value, above which $\mathrm{H}_{\mathrm{E}}$ remains constant or decreases slightly $[1,2,7,25,26]$. Exchange bias may also be strongly affected by extrinsic factors such as AFM domain formation, interfacial roughness, and grain boundaries [27-30].

In core/shell-structured NPs, the influence of the above factors becomes more complicated $[2,31]$. For example, in certain nanogranular materials, the particle-matrix crystalline mismatch has been shown to be a relevant parameter affecting the EB field and coercivity [4]. Das et al. discussed that in order to optimize EB properties, it is necessary to have irregular or defective interfaces in core/shell structures between $\mathrm{Co}$ and $\mathrm{CoO}$ [32]. Some studies have estimated a minimum AFM shell thickness required to stabilize the FM core moment and, thus, enhance blocking temperatures [5,33,34]. Feygenson et al. found that the EB field does not depend monotonically on the $\mathrm{CoO}$ shell thickness, with the highest $\mathrm{H}_{\mathrm{E}}$ value corresponding to particles with $\mathrm{Co}$ core and $\mathrm{CoO}$ shell of similar volume [27].

The optimization of EB effects in Co/Co-oxide-based nanostructures has been achieved by controlling the $\mathrm{Co}: \mathrm{CoO}$ ratio and the crystalline order of $\mathrm{CoO}$ shells via post-synthesis annealing in air [35] or high-vacuum [36], or through the control of oxygen partial pressure during sputter deposition [24]. The present work investigates core/shell Co/Co-oxide nanostructures prepared by a chemical (precipitation) method. Two different reductionoxidation treatments are employed in order to assess the effect of the FM/AFM volume ratio (which is varied over a large range by controlling the synthesis and treatment parameters) on the exchange bias field. The results show that an increase in the thickness of the AFM phase leads to different behaviors of the EB field depending on the size range of the FM core.

\section{Materials and Methods}

\subsection{Synthesis of Samples}

Samples were prepared by co-precipitation of $\mathrm{Co}\left(\mathrm{NO}_{3}\right) 3.9 \mathrm{H}_{2} \mathrm{O}$ (Merck, minimum purity of $99 \%$ ) and a domestic industrial grade of $\mathrm{NaOH}$ ( $98 \%$ purity) as the precipitant. Briefly, $58.2 \mathrm{~g}$ of the cobalt nitrate was dissolved in $200 \mathrm{~mL}$ of deionized double-distilled water, and $100 \mathrm{~mL}$ of $\mathrm{NaOH}$ solution $(3 \mathrm{~mol} / \mathrm{L})$ was added drop by drop at a uniform rate to the solution at $60^{\circ} \mathrm{C}$ using a hot plate magnetic stirrer until reaching a $\mathrm{pH}$ of 13 for the resultant mixture. After further stirring for $1 \mathrm{~h}$, a light brown precipitate was obtained. The precipitate was washed several times with distilled water to reach a neutral $\mathrm{pH}$, when the color became darker, and it was dried in air at room temperature over several days. The 
dark brown resulting precipitate (identified as $\mathrm{Co}(\mathrm{OH})_{2}$ by XRD) was used in the synthesis of two different sample series:

(i) For the $l$-series, the precipitate was calcined in air at $300{ }^{\circ} \mathrm{C}$ to yield $\mathrm{Co}_{3} \mathrm{O}_{4}$ (as identified by XRD). Then, $\mathrm{Co}_{3} \mathrm{O}_{4}$ was used to synthesize $\mathrm{Co}$ nanostructures by reduction in extra pure hydrogen gas $(99.993 \%)$ at $900{ }^{\circ} \mathrm{C}$ using a controlled-atmosphere tube furnace for $30 \mathrm{~min}$. Finally, the resulting Co particles were oxidized in pure oxygen gas at $900{ }^{\circ} \mathrm{C}$ for different time durations, namely $15,60,300$, and $540 \mathrm{~min}$, resulting in the samples that are denoted as $l(15), l(60), l(300)$, and $l(540)$, respectively.

(ii) For the s-series, the $\mathrm{Co}(\mathrm{OH})_{2}$ precursor was not calcined in air but directly reduced in hydrogen at (only) $300^{\circ} \mathrm{C}$, which allowed the formation of metallic Co particles, and subsequently oxidized also at the relatively low temperature of $300{ }^{\circ} \mathrm{C}$ for different treatment durations, resulting in the samples we label as $s(10), s(20), s(40)$, and $s(80)$, where the numbers give the duration of the oxidation treatment in minutes.

The names of the series ( $l$ or $s$ ) were chosen a posteriori from the relatively large size of the cobalt particles $(\approx 80 \mathrm{~nm}$ in diameter) present in the first series, in contrast with the smaller Co cores $(\approx 10 \mathrm{~nm}$ in diameter) observed in the second series (mainly as a result of the use of lower temperatures in the reduction and oxidation treatments).

\subsection{Structural and Magnetic Characterization Methods}

The thermal behavior of the dried precursor was studied by thermogravimetry (TG) using a TG/SDTA 851e Mettler Toledo Star System. TG curves (and subsequently the derivative curve, DTG) were obtained by heating the powder from room temperature to $900{ }^{\circ} \mathrm{C}$ at a $10^{\circ} \mathrm{C} / \mathrm{min}$ rate. X-ray diffraction (XRD) patterns of all samples were recorded using a Philips $X^{\prime}$ Pert Pro diffractometer operating in reflection mode with $\mathrm{Cu} \mathrm{K} \alpha$ radiation $(\lambda=1.5406 \AA)$ at room temperature and two different scanning rates, 0.04 and $0.02^{\circ} / \mathrm{s}$. Crystalline phases were identified using the HighScore software. Mean crystallite sizes (d) of the samples were estimated using Scherrer's formula, $d=0.9 \lambda /(B \cos \theta)$, where $\theta$ is the Bragg angle and $B$ is the full width at half maximum (in radians) of the most intense peak of each phase. Quantitative phase analysis of the XRD data was performed with a full pattern fitting procedure based on the Rietveld method using the program MAUD. Sample morphology and microstructure were studied using a field emission scanning electron microscope (Microscope GeminiSEM 500) and a transmission electron microscope (JEOL JEM-2100F).

Magnetic measurements were carried out using a Quantum Design MPMS Evercool SQUID magnetometer. Hysteresis loops were obtained at $5 \mathrm{~K}$ after cooling from room temperature in a $50 \mathrm{kOe}$ applied magnetic field. The temperature dependence of magnetization was recorded upon heating from $5 \mathrm{~K}$ to room temperature in a weak magnetic field (10 Oe) after either zero-field-cooled (ZFC) or field-cooled (FC) protocols.

\section{Result and Discussion}

Figure 1a shows the TG and DTG curves of the dried precursor $\left(\mathrm{Co}(\mathrm{OH})_{2}\right)$ measured in air. Two weight losses around 170 and $280^{\circ} \mathrm{C}$ on the TG curve indicate that the process is completed after the second loss, giving the end product. Figure $1 \mathrm{~b}$ shows the XRD pattern of the calcined precipitate obtained at $300^{\circ} \mathrm{C}$ in air for $2 \mathrm{~h}$. The main peaks are assigned to the spinel crystal structure of $\mathrm{Co}_{3} \mathrm{O}_{4}$ and indicate a mean crystallite size of $35 \mathrm{~nm}$. Therefore calcination of the $\left(\mathrm{Co}(\mathrm{OH})_{2}\right.$ precursor at $300{ }^{\circ} \mathrm{C}$ results in the nanocrystalline of $\mathrm{Co}_{3} \mathrm{O}_{4}$, which was used as stock to synthesize Co nanoparticles via reduction in hydrogen. 

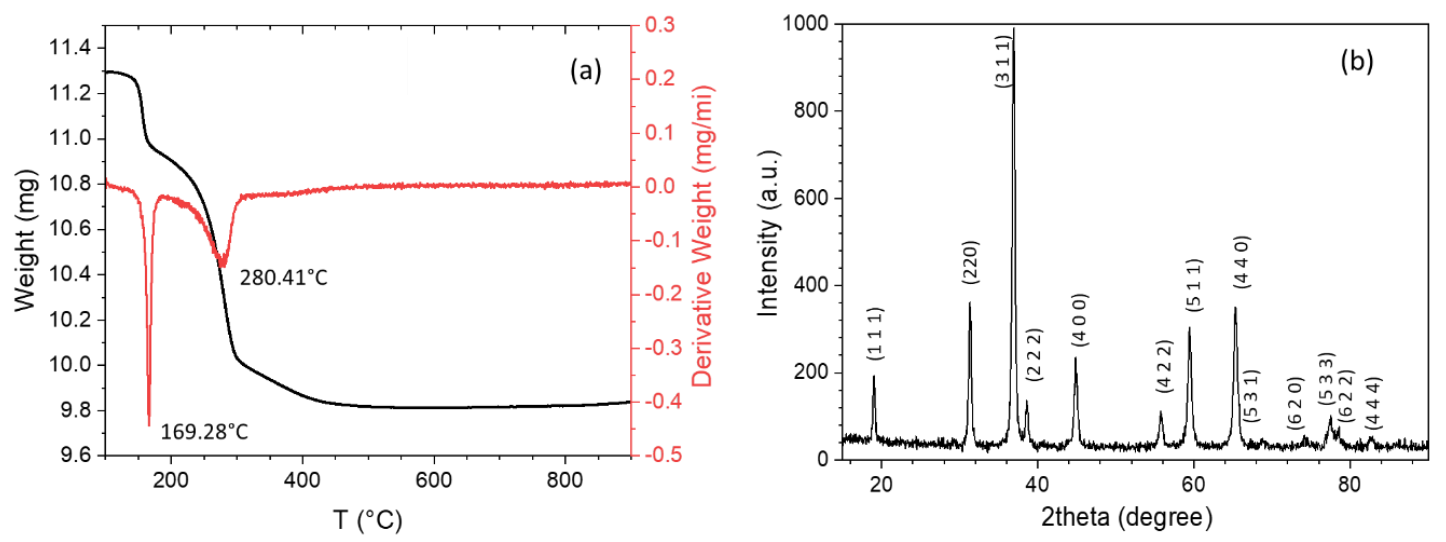

Figure 1. (a) Thermogravimetric curve and its derivative of the dried $\mathrm{Co}(\mathrm{OH})_{2}$ precipitate, and (b) XRD pattern of the sample calcined at $300{ }^{\circ} \mathrm{C}$ in air (the Bragg reflections are labeled according to $\mathrm{Co}_{3} \mathrm{O}_{4}$, PDF card No. 01-080-1545).

Figure 2 shows XRD patterns of the $l$-series samples that were reduced and oxidized at $900{ }^{\circ} \mathrm{C}$ for different treatment durations (the same in both). In the XRD patterns of the $l(15), l(60)$, and $l(300)$ samples, the main peaks correspond to fcc (face-centered cubic) $\mathrm{CoO}$, but there are also some lower intensity peaks of both cubic and hexagonal $\mathrm{Co}$. As expected, upon oxidation for longer times, the intensity of the $\mathrm{Co}$ oxide peaks-first $\mathrm{CoO}$ and eventually $\mathrm{Co}_{3} \mathrm{O}_{4}$-increase at the expense of the metallic Co reflections. The sample oxidized for the longest time, i.e., $l(540)$, shows a majority presence of $\mathrm{Co}_{3} \mathrm{O}_{4}$, with some $\mathrm{CoO}$ remaining but no metallic $\mathrm{Co}$. The high-temperature $\left(\mathrm{T}=900^{\circ} \mathrm{C}\right)$ oxidation causes a concomitant crystallization process, as indicated by the relatively sharp peaks in the XRD patterns. The corresponding Scherrer grain sizes, a lower-bound estimate of the real grain size given that strain and instrumental broadening have not been considered, are summarized in Table 1. The relatively large Co grain sizes obtained (evidencing Co cores at least that size) justifies the name " $l$-series" for these samples. The percentages of Co-oxide shell and Co core, also shown in Table 1, were obtained by quantitative phases analysis from Rietveld-based pattern fits using the MAUD program.

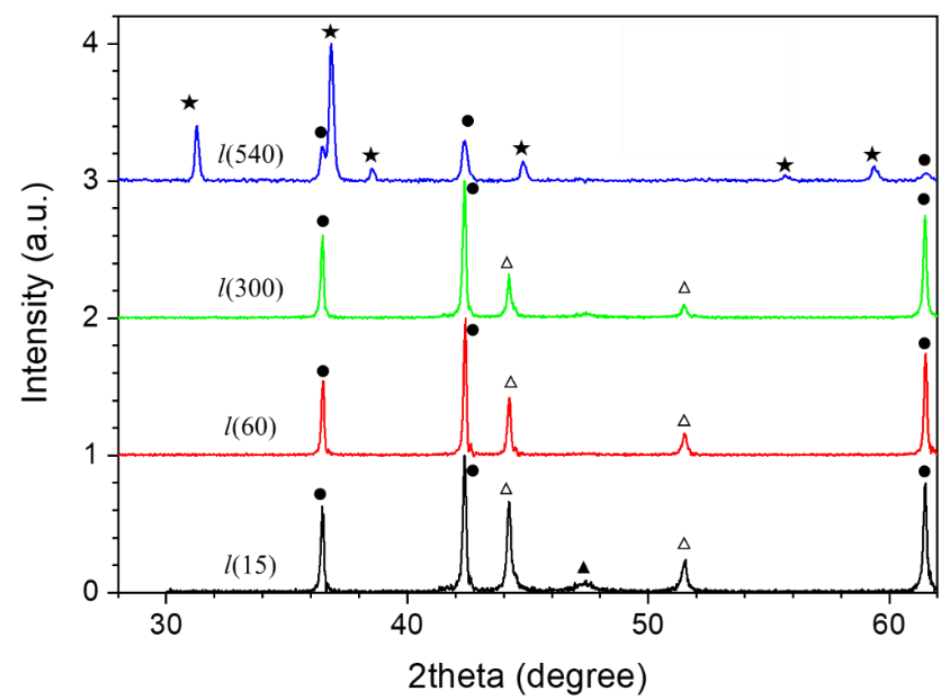

Figure 2. XRD patterns of $l$-series for various oxidation times. The symbols next to different reflections indicate their assigned phases: $(\bullet) \mathrm{CoO}\left(00-048-1719 \mathrm{PDF}\right.$ card No.), ( $\star$ ) $\mathrm{Co}_{3} \mathrm{O}_{4}(01-080-1542 \mathrm{PDF}$ card No.), $(\triangle$ ) cubic Co (00-015-0806 PDF card No.), and ( $\mathbf{\Lambda}$ ) hexagonal Co (00-005-0727 PDF card No.). 
Table 1. Summary of compositional and structural parameters extracted from magnetometry and XRD for the $l$-series. $M_{S}$ denotes saturation magnetization.

\begin{tabular}{|c|c|c|c|c|c|c|}
\hline Sample & $\begin{array}{l}\text { Co-Oxide Percentage } \\
\left(1-\left(M_{S} / M_{S, b u l k}\right)\right) \times 100\end{array}$ & $\begin{array}{c}\text { Co Percentage } \\
\left(\mathrm{M}_{\mathrm{S}} / \mathrm{M}_{\mathrm{S}, \mathrm{bulk}}\right) \times 100\end{array}$ & $\begin{array}{l}\text { Co-Oxide } \\
\text { Percentage } \\
\text { (XRD) }\end{array}$ & $\begin{array}{l}\text { Co Percentage } \\
\text { (XRD) }\end{array}$ & $\begin{array}{c}\text { Co-Oxide } \\
\text { Crystallite Size } \\
(\mathrm{nm})\end{array}$ & $\begin{array}{l}\text { Co Crystallite } \\
\text { Size }(\mathrm{nm})\end{array}$ \\
\hline$l(15)$ & 51.9 & 48.1 & 56.4 & 43.6 & 89 & 92 \\
\hline$l(60)$ & 65.5 & 34.5 & 73.3 & 26.7 & 94 & 74 \\
\hline$l(300)$ & 67.7 & 32.3 & 75.9 & 24.1 & 107 & 70 \\
\hline$l(540)$ & 98 & 2 & 100 & 0 & 65 & 0 \\
\hline
\end{tabular}

Low-temperature hysteresis loops of the $l$-series samples are shown in Figure 3. As expected, the saturation magnetization, $\mathrm{M}_{\mathrm{S}}$, is drastically reduced upon oxidation, evidencing the progressive growth of a Co-oxide shell at the expense of the Co core. All loops exhibit horizontal shifts (EB fields), indicating the exchange coupling between Co cores and Co-oxide shells. The variation of saturation magnetization $\left(\mathrm{M}_{\mathrm{S}}\right), \mathrm{H}_{\mathrm{E}}$ and coercivity $\left(\mathrm{H}_{\mathrm{C}}\right)$ with oxidation time is presented in Figure 4. The normalization of the measured $\mathrm{M}_{\mathrm{S}}$ (after subtracting high-field linear contributions) by the bulk magnetization of cobalt, $\mathrm{M}_{\mathrm{S}, \text { bulk }}=160 \mathrm{emu} / \mathrm{g}$, gives an estimate of the Co and Co-oxide weight fractions in each sample. These values are shown in the last two columns of Table 1. Although they compare reasonably well with the Co and Co-oxide fractions obtained from the XRD fits, the values obtained by magnetometery show systematically higher Co fractions. This could be attributed to an FM-like contribution in the mostly AFM Co-oxide phases due to crystalline disorder or size effects, as reported previously for different AFM nanostructures [37-41]. For the most oxidized sample, $l(540)$, magnetometery proves far more sensitive than XRD to detect the presence of a residual ( $2 \%)$ amount of metallic Co.

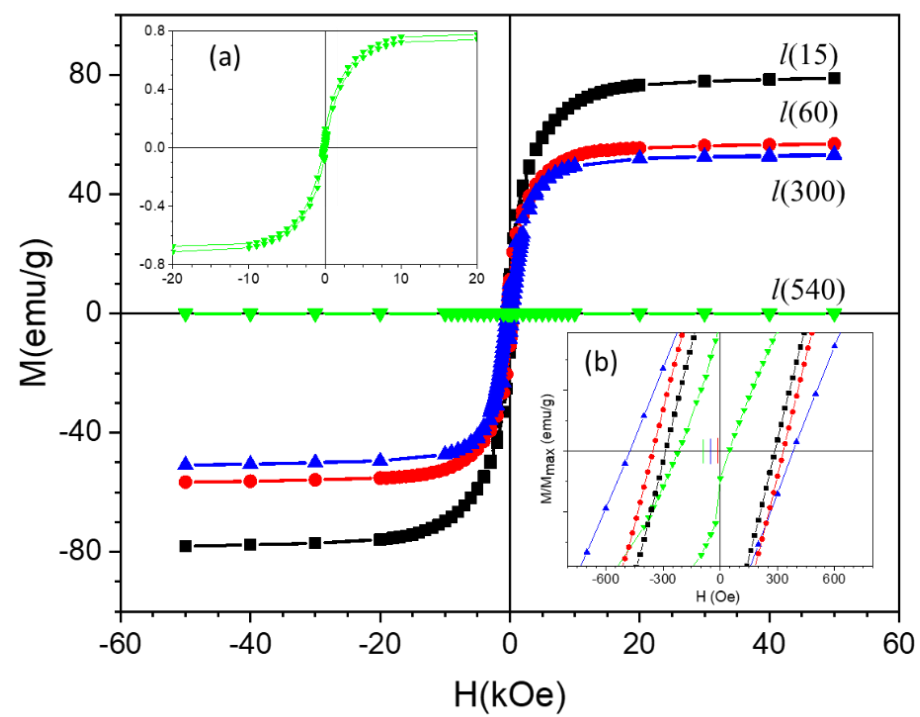

Figure 3. Hysteresis loops at $5 \mathrm{~K}$ after field-cooling (in $50 \mathrm{kOe}$ ) of the $l$-series samples. Insets: (a) hysteresis loop of the most oxidized sample of the series, l(540), and (b) zoom-in of the low-field region (the vertical bars on the $\mathrm{H}$ axis mark the centers of the different loops, i.e., the exchange bias field of each sample). 


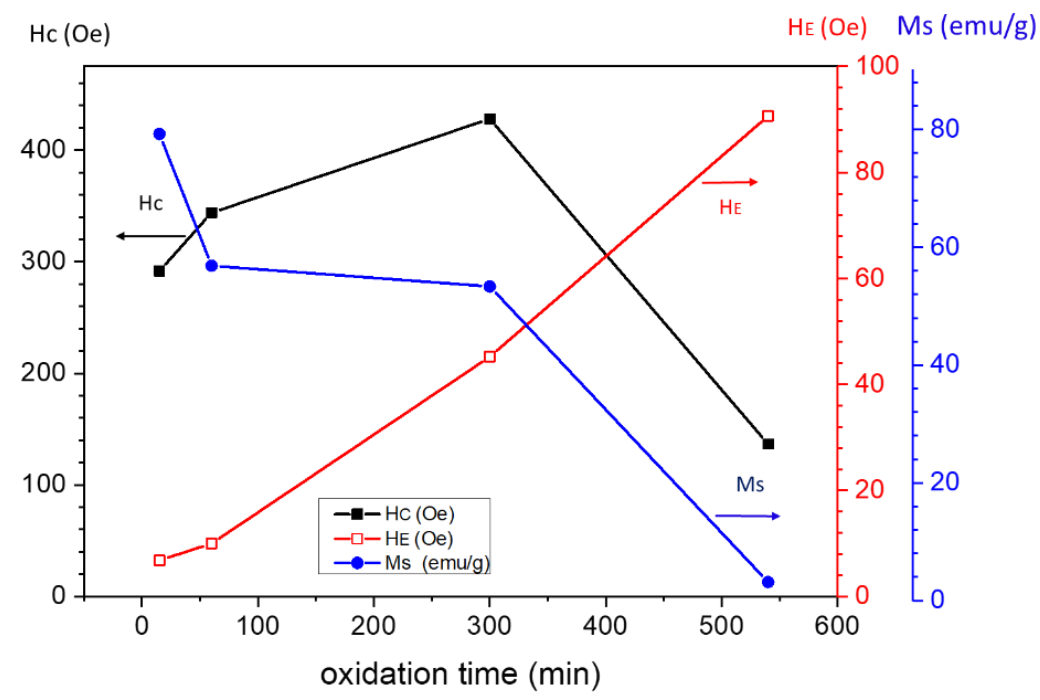

Figure 4. Variation of the saturation magnetization $\left(\mathrm{M}_{\mathrm{s}}\right)$, coercivity $\left(\mathrm{H}_{\mathrm{c}}\right)$, and the absolute value of the exchange bias $\left(\mathrm{H}_{\mathrm{E}}\right)$ with respect to oxidation time for the $l$-series.

These hysteresis loops present a modest coercivity, which increases slightly with oxidation and peaks for $l(300)$. As expected for the large FM cores in this series, the EB field is rather modest across the series, and therefore, its (correspondingly small) contribution to the effective magnetic anisotropy [42] is unlikely to be the reason for the coercivity increase. Rather, it may simply be due to the size reduction with the oxidation of a fraction of multidomain cores, the presence of which is plausible given the relatively large size of the cores in this series [43]. After oxidizing for the longest time, i.e., sample l(540), only a residue of metallic Co remains, which is undetectable by XRD (Figure 2), yielding a small ferromagnetic contribution (below $1 \mathrm{emu} / \mathrm{g}$ ) to the magnetic response (upper inset in Figure 3). At this almost complete stage of oxidation, the Co residue is expected to be in the form of very small nanoparticles embedded in the Co oxide matrix, thus showing a decreased coercivity even if blocked at $5 \mathrm{~K}$ (the temperature at which the loops were measured). In fact, the FC-ZFC magnetization curves shown in Figure 5a shows that l(540) contains a fraction of Co NPs so small that they become superparamagnetic above a blocking temperature as low as $50 \mathrm{~K}$. Figure $5 \mathrm{~b}$ presents the temperature dependence of $\mathrm{H}_{\mathrm{E}}$ in this sample, which vanishes right about the blocking temperature signaled by the FC-ZFC irreversibility in the upper panel, pointing out that the magnetic stability of these ultrafine particles is governed by their exchange coupling to the Co oxide phase in which they are embedded. Moreover, the exchange bias onset temperature $(\approx 50 \mathrm{~K})$ is close to the Néel temperature of $\mathrm{Co}_{3} \mathrm{O}_{4}(40 \mathrm{~K})[44,45]$, which is in good agreement with the XRD pattern of this sample (where the majority phase is $\mathrm{Co}_{3} \mathrm{O}_{4}$, but a fraction of $\mathrm{CoO}$ is still detected, which may act to increase the effective EB onset temperature).

In the above series, the metallic Co regions (excluding perhaps a certain fraction in l(540)) were too large to yield strong EB fields. Next, the results corresponding to the s-series are presented, beginning with the XRD patterns in Figure 6, where, again, growing fractions of $\mathrm{CoO}$ and $\mathrm{Co}_{3} \mathrm{O}_{4}$, at the expense of cubic $\mathrm{Co}$, upon oxidation are observed. However, a fraction of metallic nanocrystalline Co remains after oxidation for $80 \mathrm{~min}$. In fact, samples $s(40)$ and $s(80)$ present very similar patterns, suggesting an effective passivation of the system after $40 \mathrm{~min}$. As expected, crystallinity improves with longer thermal treatment. The fractions of the Co-oxide shell and Co core were estimated using the program MAUD and are presented in Table 2. 


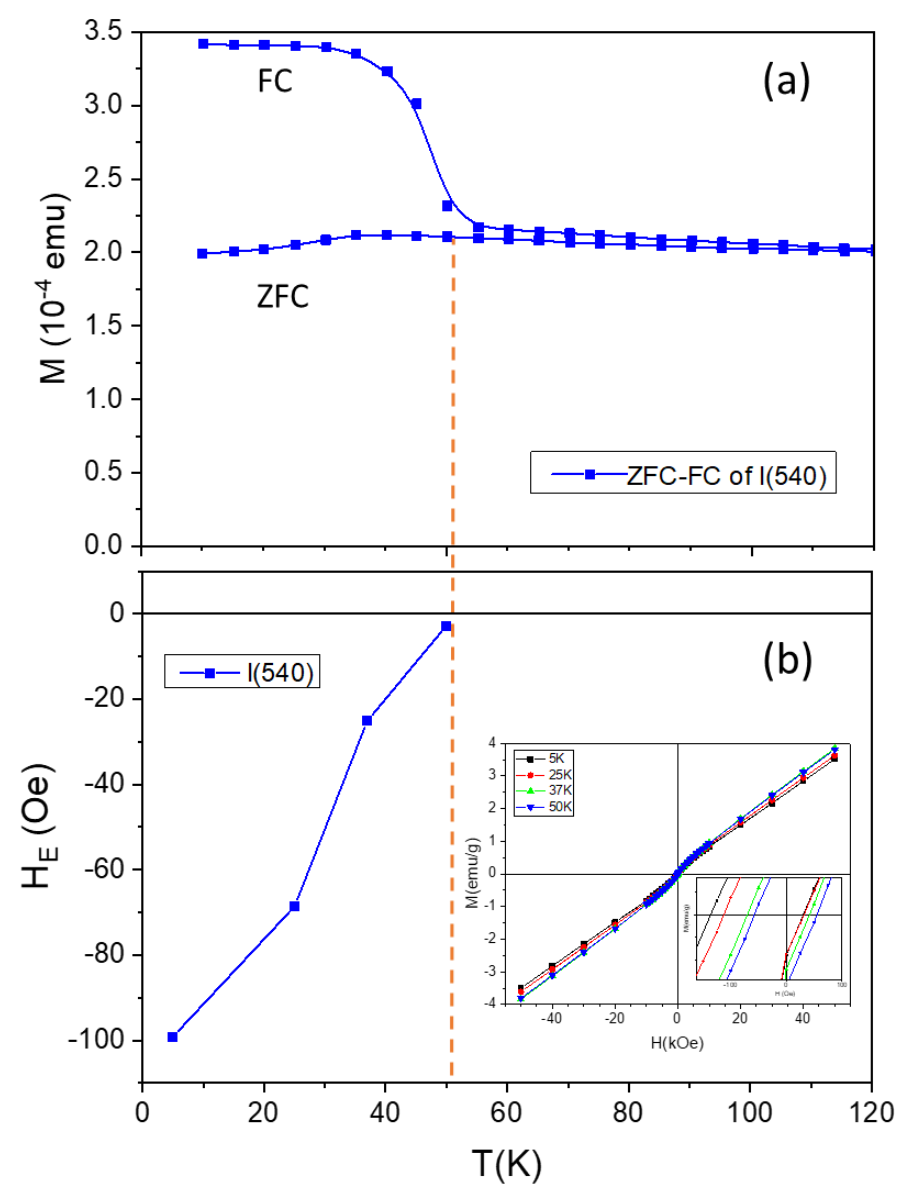

Figure 5. Temperature dependence of (a) field-cooled (FC) and zero-field-cooled (ZFC) magnetization curves measured in an applied field of $\mathrm{H}=5 \mathrm{Oe}$ and $(\mathbf{b})$ the exchange bias field. The solid lines are guides to the eye. The dashed vertical line (at $\mathrm{T}=52 \mathrm{~K}$ ) indicates how the onset of exchange bias in $l(540)$ is related to the bifurcation temperature of the ZFC and FC curves.

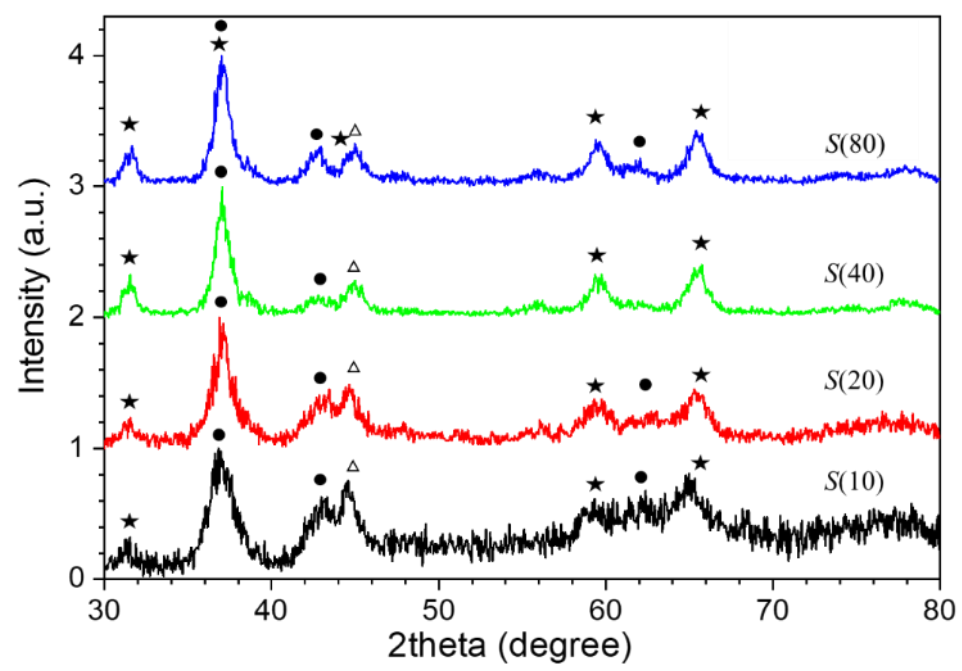

Figure 6. XRD patterns of the s-series, where the number in the sample names is the oxidation time in minutes. The symbols indicate peaks of the following phases: (•) CoO (PDF card No. 01-075-0533), $(\star) \mathrm{Co}_{3} \mathrm{O}_{4}$ (PDF card No. 00-001-1152), and $(\triangle)$ cubic Co (PDF card No. 00-015-0806). 
Table 2. Summary of compositional and structural parameters extracted from magnetometry and XRD for the $s$-series. $\mathrm{M}_{\mathrm{S}}$ denotes saturation magnetization.

\begin{tabular}{|c|c|c|c|c|c|c|}
\hline Sample & $\begin{array}{c}\text { Co-Oxide Percentage } \\
\left(1-\left(M_{S} / M_{S, b u l k}\right)\right) \times 100\end{array}$ & $\begin{array}{c}\text { Co Percentage } \\
\left(\mathrm{M}_{\mathrm{S}} / \mathrm{M}_{\mathrm{S}, \mathrm{bulk}}\right) \times 100\end{array}$ & $\begin{array}{l}\text { Co-Oxide } \\
\text { Percentage } \\
\text { (XRD) }\end{array}$ & $\begin{array}{l}\text { Co Percentage } \\
\text { (XRD) }\end{array}$ & $\begin{array}{c}\text { Co-Oxide } \\
\text { Crystallite Size } \\
(\mathrm{nm})\end{array}$ & $\begin{array}{l}\text { Co Crystallite } \\
\text { Size }(\mathrm{nm})\end{array}$ \\
\hline$s(10)$ & 87.9 & 12.1 & 73 & 27 & 8 & 13 \\
\hline$s(20)$ & 89.7 & 10.3 & 77 & 23 & 14.5 & 10 \\
\hline$s(40)$ & 93.9 & 6.1 & 81 & 19 & 14 & 9.7 \\
\hline$s(80)$ & 94 & 6 & 82 & 18 & 13 & 11 \\
\hline
\end{tabular}

Figure 7a-h show the results of a transmission electron microscopy (TEM) study of the $s(10)$ and $s(40)$ samples, where the roughly spherical aggregated (or partially sintered) nanoscale grains with a relatively narrow size distribution can be seen. These small grains are sometimes organized into nanorods with a mean diameter of $\sim 15 \mathrm{~nm}$ and a length of $\sim 80 \mathrm{~nm}$ for $s(10)$, see Figure $7 \mathrm{~b}$, and the same mean diameter and a length of $\sim 140 \mathrm{~nm}$ for $s(40)$, see Figure $7 f$. This suggests that longer thermal treatments produce further directional aggregation/sintering. Figure $7 \mathrm{~b}-\mathrm{f}$ display higher magnification images and include arrows indicating the length of some of these nanorods in both samples. The high-resolution (HRTEM) micrographs in Figure 7c,d show the nanograins that make up the rods. The size of these crystallites, between 11 and $16 \mathrm{~nm}$ in diameter, is in good agreement with the Scherrer sizes obtained from the XRD patterns (Figure 6).
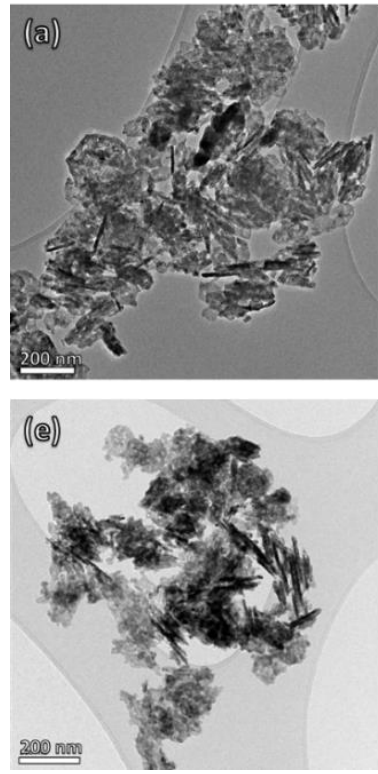
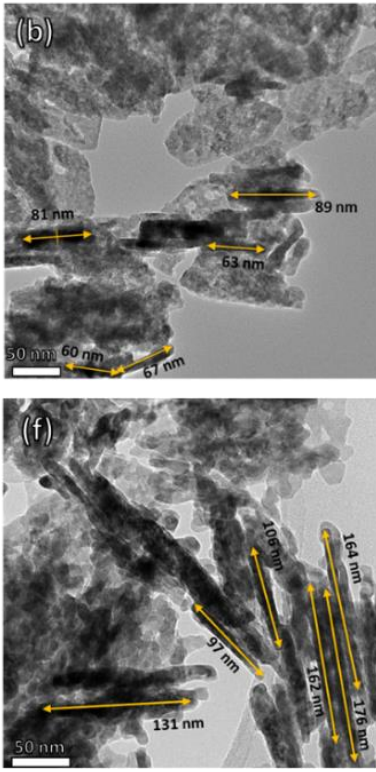
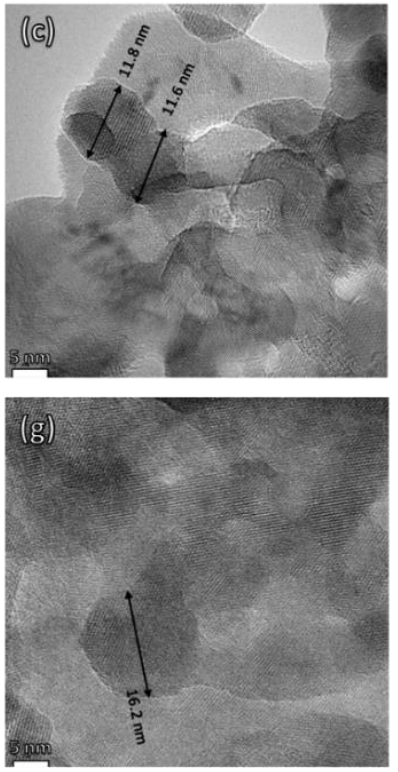
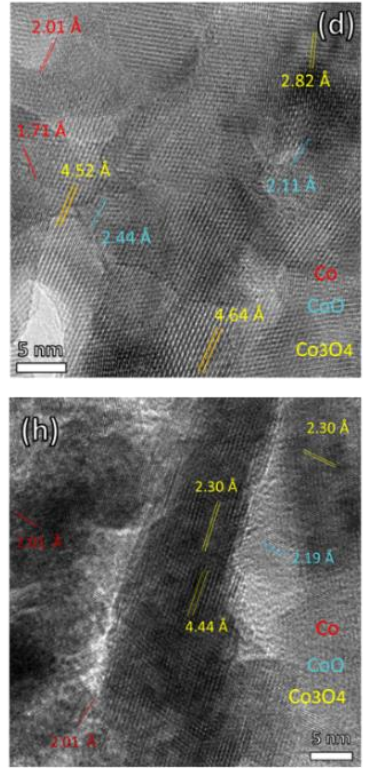

Figure 7. Transmission electron micrographs of samples $s(10)$ [top row; (a-d)] and $s(40)$ [bottom row; (e,f)]. The different micrographs correspond to different resolutions, indicated by their scale bars: namely $200 \mathrm{~nm}$ in $(\mathbf{a}, \mathbf{e}), 50 \mathrm{~nm}$ in $(\mathbf{b}, \mathbf{f})$, and $5 \mathrm{~nm}$ in $(\mathbf{c}, \mathbf{d}, \mathbf{g}, \mathbf{h})$.

The HRTEM images in Figure 7d-h show various crystalline domains, which also present some contrast consistent with a mixture of metallic Co and Co oxides phases. As indicated by the color code, the observed interplanar spacings are consistent with fcc $\mathrm{Co}_{3} \mathrm{O}_{4}$ [(111) and (222) planes], fcc $\mathrm{CoO}$ [(200) plane], and (2.01 $\mathrm{A}$ ) consistent with fcc Co [(111) plane]. Figure $7 \mathrm{~h}$ indicates that the nanorod in the image is a single crystal of $\mathrm{Co}_{3} \mathrm{O}_{4}$ with the (111) and (222) planes oriented along the rod axis, whereas Figure $7 \mathrm{~d}$ shows a fine polycrystalline nanostructure. Thus, the nanorod coexists with other aggregation, less well-defined, nanostructures.

Figure 8 shows the low-temperature $(5 \mathrm{~K})$ hysteresis loops measured in the $s$-series. The inset displays the hysteretic (low-field) region. All loops have a considerable coercivity, 
and a clear shift along the field axis, stronger than in the $l$-series, which again is attributed to the exchange coupling between Co core and Co-oxide shell. Figure 9 presents the values of these (coercive and EB) fields, together with the technical saturation magnetizations (at $50 \mathrm{kOe}$ ), extracted from the loops in Figure 8. The magnetization values are smaller than in the $l$-series (except for the nearly completely oxidized $l(540)$ ), indicating a smaller fraction of metallic Co (the estimated values are shown in Table 2). Not only is the fraction of Co lower than in the $l$-series, but the Co particles are smaller, as discussed above from XRD and TEM, explaining the stronger EB fields in this series.

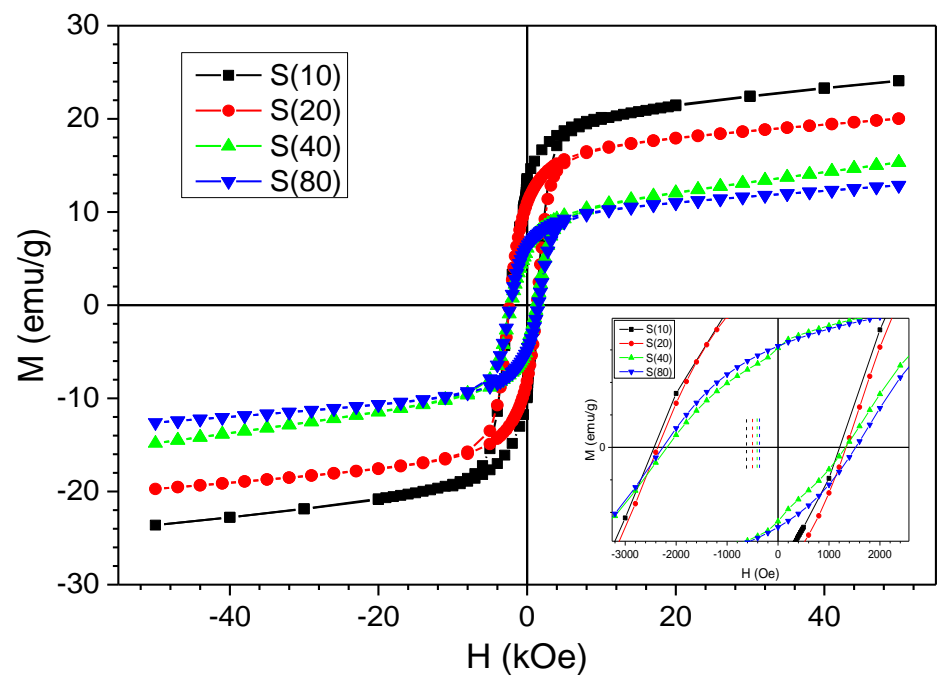

Figure 8. Hysteresis loops of $s$-series samples recorded at $5 \mathrm{~K}$ after field-cooled ( $50 \mathrm{kOe})$. The numbers in the legend are the oxidation times in minutes. Inset: zoom-in of low field portions of the loops.

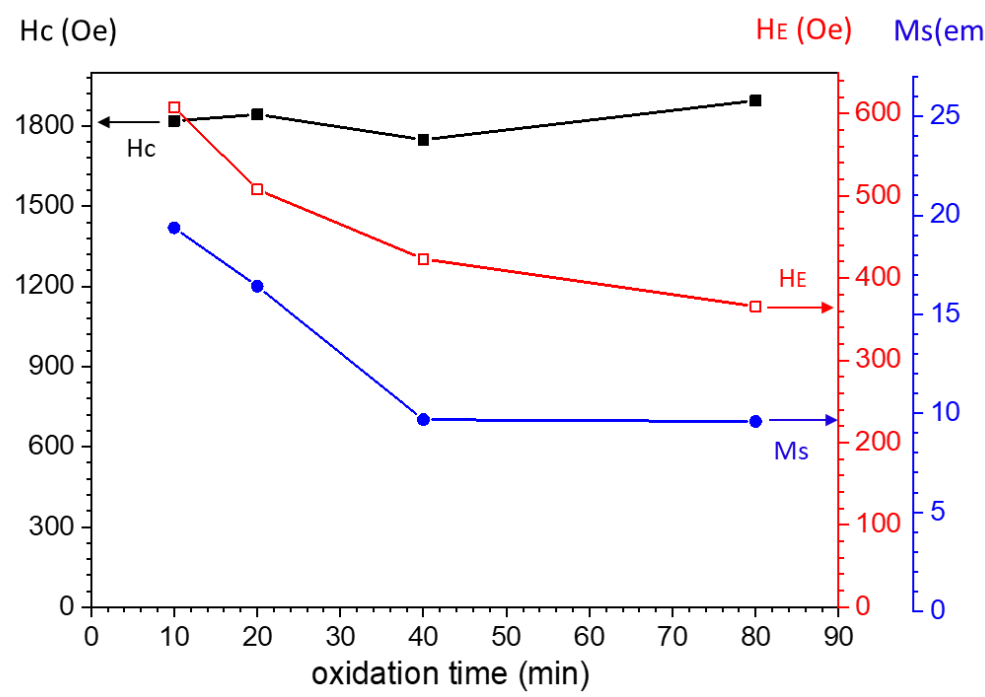

Figure 9. Variation of the saturation magnetization $\left(\mathrm{M}_{\mathrm{S}}\right)$, coercivity $\left(\mathrm{H}_{\mathrm{C}}\right)$, and (absolute values of) exchange bias field $\left(\mathrm{H}_{\mathrm{E}}\right)$ as a function of oxidation time (s-series).

In addition to the effect of the core size in explaining the higher $\mathrm{H}_{\mathrm{E}}$ in the s-series (FM cores $\approx 10 \mathrm{~nm}$ in diameter) compared to the $l$-series (FM cores $\approx 100 \mathrm{~nm}$ in diameter), AFM anisotropy and the interface conditions also play an important role in the complex EB phenomenon [27,35], and these factors possibly become particularly relevant in the $s$-series, where the variation in FM core size is relatively small. This is emphasized by the continuous decrease in $\mathrm{H}_{\mathrm{E}}$ across the entire series despite the apparent passivation after oxidizing for $40 \mathrm{~min}$; i.e., samples $s(40)$ and $s(80)$ have identical saturation magnetizations. López-Antón et al. optimized $\mathrm{H}_{\mathrm{E}}$ to about $7 \mathrm{kOe}$ after oxidizing Co NPs (around $6 \mathrm{~nm}$ 
in diameter) to roughly half of their initial saturation magnetization, after which further oxidation produced a marked and progressive reduction in exchange bias. In the present case, the size of the highest $\mathrm{H}_{\mathrm{E}}$ measured $(600 \mathrm{Oe})$ and the considerable oxidation (about $88 \%$, see Table 2) of even sample $s(10)$ suggests that this first sample of the $s$-series is already past the optimum oxidation degree for achieving enhanced EB properties. The subsequent decrease in EB properties in the s-series can be attributed, following the above authors, to a progressive reduction in the density of uncompensated spins in the AFM components at their interfaces with Co cores. In contrast, in the $l$-series, the high temperature of the treatments $\left(900^{\circ} \mathrm{C}\right)$ probably achieved the "saturation" of the degree of AFM order already for the first sample of the series [l(15)], as suggested by the high crystallinity observed by XRD (see Figure 2). In any case, if there was a small variation in the degree of AFM order (and, concomitantly, in uncompensated spin density) across that series, its effect on EB properties would likely be negligible compared to the the FM core size effect, as the variation of the size of the Co regions in the $l$-series (see Table 1 ) is much larger than in the $s$-series (where it is virtually negligible; see Table 2). Dobrynin et al.'s model [46], which considers a critical FM core size below which there is no EB effect due to the lack of magnetization reversal of a FM moment fully pinned across the whole applied field range, is probably not relevant for the FM core range in the s-series, but a contribution from this mechanism to the decreasing $\mathrm{H}_{\mathrm{E}}$ cannot be ruled out.

Figure 10 shows the temperature dependence of the EB field in the sample with the highest $\mathrm{H}_{\mathrm{E}}$, namely $s(10)$. The onset of $\mathrm{H}_{\mathrm{E}}$ takes place at about $210 \mathrm{~K}$ (extrapolating the line, a guide to the eye, drawn through the data points in the figure), which indicates that the $\mathrm{Co}$ regions are exchange-coupled mainly to $\mathrm{CoO}$ and less to $\mathrm{Co}_{3} \mathrm{O}_{4}$ (with a much lower Néel temperature) [2,27,47-49], which is consistent with the larger fraction of this oxide detected by XRD.

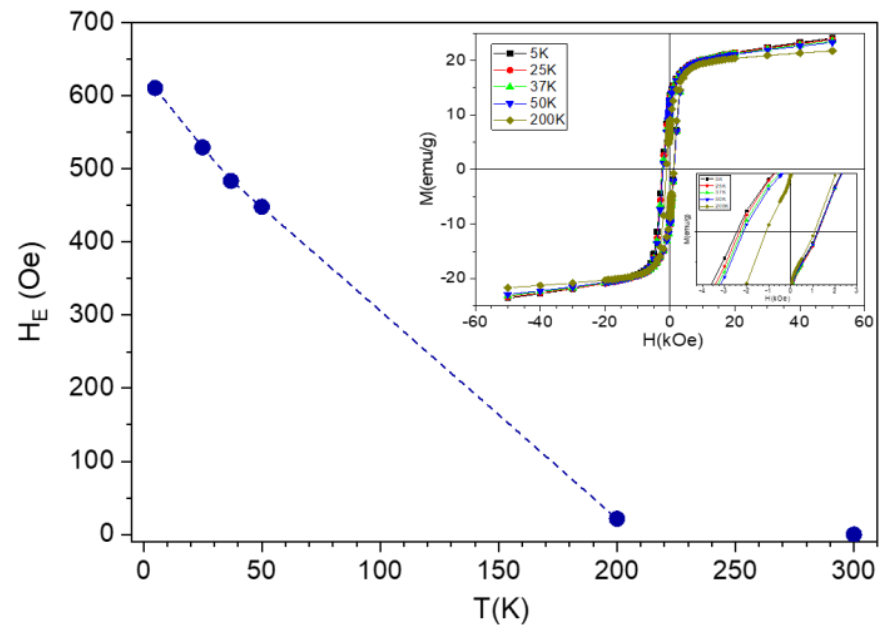

Figure 10. Temperature dependence of the exchange bias field in sample $s(10)$.

Coercivity $\left(\mathrm{H}_{\mathrm{C}} \approx 1.8 \mathrm{kOe}\right)$ is more than five times larger than in the $l$-series. This is consistent with the much stronger EB fields in the s-series, as coercivity enhancement is a well-known effect of FM-AFM exchange coupling in nanostructures, which effectively provides a contribution to the magnetic anisotropy $[2,50]$. However, it is somewhat surprising (e.g., in comparison with the results of Lopez-Antón et al. [35]) that the coercivity barely changes (with oxidation) across the series. If, as suggested above to explain the decrease in $\mathrm{H}_{\mathrm{C}}$, progressively longer oxidation thermal treatments reduce the density of interfacial (AFM) uncompensated spins, then the remaining spins must become more rotatable in order to compensate the coercivity for the loss of uncompensated spins (it is these spins, as opposed to fully pinned spins, that enhance the coercivity as they are partially dragged by the magnetization reversal in the FM cores [51,52]). In fact, a combination of both factors 
(namely, decrease of uncompensated spins and softening of their pinning potential upon annealing-enhanced oxidation) also may explain the data.

\section{Conclusions}

In this work, two series of $\mathrm{Co} / \mathrm{Co}$-oxide nanostructured materials comprising Co particles in two clearly different size ranges $(\approx 10$ and $\approx 100 \mathrm{~nm}$ ) have been investigated through the examination of their magnetic and structural properties as a function of post-synthesis oxidation time at $300{ }^{\circ} \mathrm{C}$ (s-series) and at $900{ }^{\circ} \mathrm{C}$ ( $($-series $)$, which increases the oxide fraction at the expense of the Co cores but also has been inferred to affect the interface details.

A contrasting evolution of the exchange bias upon sample oxidation has been found for the two series. For the large ferromagnetic cores in the $l$-series, $\mathrm{H}_{\mathrm{E}}$ increases as expected from the well-known $\mathrm{H}_{\mathrm{E}} \propto 1 / \mathrm{M}_{\mathrm{FM}}$ law, whereas the progressive oxidation of the small Co cores present in the s-series produces a monotonic reduction of the loop shift. The latter result is ascribed to a modification of the crystalline ordering of the FM-AFM interface with annealing time, which renders a lower density of uncompensated spins. In the $l$-series, this mechanism is likely saturated already in the first sample of the series. Overall, our experiments offer insight on the relative importance of FM core size (in the 10-100 nm range) and interface crystalline order in the determination of the exchange bias field.

Author Contributions: Conceptualization, M.G. and M.M.; methodology, M.G. and M.M., J.A.D.T., P.S.N.; validation, M.M., J.A.D.T., P.S.N., A.A.-N.; formal analysis, M.G. and M.M., J.A.D.T., P.S.N., A.A.-N.; investigation, M.G.; resources, M.M., J.A.D.T.; data curation, M.M., J.A.D.T., P.S.N., A.A.-N.; writing—original draft preparation, M.G.; writing—review and editing, M.G., M.M., J.A.D.T., P.S.N.; visualization, M.G.; supervision, M.M., J.A.D.T., P.S.N.; project administration, M.M., J.A.D.T., P.S.N.; funding acquisition, M.M., J.A.D.T. All authors have read and agreed to the published version of the manuscript.

Funding: P.S.N. and J.A.D.T. acknowledge financial support from the Spanish Ministerio de Economia y Competitividad, MINECO (grant MAT2015-65295).

Institutional Review Board Statement: Not applicable.

Informed Consent Statement: Not applicable.

Data Availability Statement: Not applicable.

Acknowledgments: We would like to thank Eduardo Prado for his SEM support, Sara Shatooti for her kind help in the preparation of some samples, and Salim H. Al-Harthi, Ali A Yousif and Myo Tay Zar Myint for their kind help in for their TEM supports.

Conflicts of Interest: The authors certify that they have NO affiliations with or involvement in any organization or entity with any financial interests (such as honoraria; educational grants; participation in speakers' bureaus; membership, employment, consultancies, stock ownership, or other equity interests; and expert testimony or patent-licensing arrangements), or non-financial interests (such as personal or professional relationships, affiliations, knowledge or beliefs) in the subject matter or materials discussed in this manuscript.

\section{References}

1. Nogués, J.; Sort, J.; Langlais, V.; Skumryev, V.; Suriñach, S.; Muñoz, J.S.; Baró, M.D. Exchange bias in nanostructures. Phys. Rep. 2005, 422, 65-117. [CrossRef]

2. López-Ortega, A.; Estrader, M.; Salazar-Alvarez, G.; Roca, A.G.; Nogués, J. Applications of exchange coupled bi-magnetic hard/soft and soft/hard magnetic core/shell nanoparticles. Phys. Rep. 2015, 553, 1-32. [CrossRef]

3. Vatansever, Z.D.; Vatansever, E. Tunning exchange bias in inverted antiferromagnetic/ferromagnetic core/shell nanoparticles by binary alloy shells. Phys. Lett. A 2018, 382, 2901-2907. [CrossRef]

4. González, J.A.; Andrés, J.P.; López Antón, R.; De Toro, J.A.; Normile, P.S.; Muniz, P.; Riveiro, J.M.; Nogués, J. Maximizing Exchange Bias in $\mathrm{Co} / \mathrm{CoO}$ Core/Shell Nanoparticles by Lattice Matching between the Shell and the Embedding Matrix. Chem. Mater. 2017, 29, 5200-5206. [CrossRef]

5. Thomas, S.; Reethu, K.; Thanveer, T.; Myint, M.T.Z.; Al-Harthi, S.H. Effect of shell thickness on the exchange bias blocking temperature and coercivity in Co-CoO core-shell nanoparticles. J. Appl. Phys. 2017, 122, 063902. [CrossRef] 
6. Obaidat, I.M.; Nayek, C.; Manna, K.; Bhattacharjee, G.; Al-Omari, I.A.; Gismelseed, A. Investigating exchange bias and coercivity in Fe3O4- $\gamma$-Fe2O3 core-shell nanoparticles of fixed core diameter and variable shell thicknesses. Nanomaterials $2017,7,415$. [CrossRef]

7. Nogués, J.; Schuller, I.K. Exchange Bias. J. Magn. Magn. Mater. 1999, 192, 203-232. [CrossRef]

8. Giri, S.; Patra, M.; Majumdar, S. Exchange bias effect in alloys and compounds. J. Phys. Condens. Matter 2011, $23,073201$. [CrossRef]

9. Eftaxias, E.; Trohidou, K.N. Numerical study of the exchange bias effects in magnetic nanoparticles with core/shell morphology. Phys. Rev. B 2005, 71, 134406. [CrossRef]

10. Ghoshani, M.; Mozaffari, M.; Al-nabhani, A. Influence of milling time on the structural and exchange bias of CoO and Co-Co oxide nanocomposite systems. Ceram. Int. 2021, 47, 5133-5144. [CrossRef]

11. González, J.A.; Andrés, J.P.; De Toro, J.A.; Muñiz, P.; Muñoz, T.; Crisan, O.; Binns, C.; Riveiro, J.M. Co-CoO nanoparticles prepared by reactive gas-phase aggregation. J. Nanopart. Res. 2009, 11, 2105-2111. [CrossRef]

12. Riveiro, J.M.; De Toro, J.A.; Andrés, J.P.; González, J.A.; Muñoz, T. Exchange-bias stabilization of the magnetic nanoparticles in a granular alloy grown by reactive sputtering. Appl. Phys. Lett. 2005, 86, 172503. [CrossRef]

13. Salazar, J.S.; Perez, L.; De Abril, O.; Phuoc, L.T.; Ihiawakrim, D.; Vazquez, M.; Greneche, J.; Begin-colin, S.; Pourroy, G. Magnetic Iron Oxide Nanoparticles in 10-40 nm Range: Composition in Terms of Magnetite/Maghemite Ratio and Effect on the Magnetic Properties. Chem. Mater. 2011, 23, 1379-1386. [CrossRef]

14. Falk, R.B.; Hooper, G.D. Elongated Iron-Cobalt: Ferrite, a New, Lightweight, Permanent Magnet Material. J. Appl. Phys. 1961, 32, 190-192. [CrossRef]

15. Dimitrov, D.V.; van Ek, J.; Li, Y.F.; Xiao, J.Q. Enhanced magnetic stability in spin valves with synthetic antiferromagnet. J. Appl. Phys. 2000, 87, 6427-6429. [CrossRef]

16. Kools, J.C.S. Exchange-biased spin-valves for magnetic storage. IEEE Trans. Magn. 1996, 32, 3165-3184. [CrossRef]

17. Gurney, B.A.; Speriosu, V.S.; Wilhoit, D.R.; Lefakis, H.; Fontana, R.E.; Heim, D.E.; Dovek, M. Can spin valves be reliably deposited for magnetic recording applications? J. Appl. Phys. 1997, 81, 3998-4003. [CrossRef]

18. Estrader, M.; López-Ortega, A.; Estradé, S.; Golosovsky, I.V.; Salazar-Alvarez, G.; Vasilakaki, M.; Trohidou, K.N.; Varela, M.; Stanley, D.C.; Sinko, M.; et al. Robust antiferromagnetic coupling in hard-soft bi-magnetic core/shell nanoparticles. Nat. Commun. 2013, 4, 2960. [CrossRef]

19. López-Ortega, A.; Lottini, E.; Bertoni, G.; De Julián Fernández, C.; Sangregorio, C. Topotaxial Phase Transformation in Cobalt Doped Iron Oxide Core/Shell Hard Magnetic Nanoparticles. Chem. Mater. 2017, 29, 1279-1289. [CrossRef]

20. Balakrishnan, P.B.; Silvestri, N.; Fernandez-Cabada, T.; Marinaro, F.; Fernandes, S.; Fiorito, S.; Miscuglio, M.; Serantes, D.; Ruta, S.; Livesey, K.; et al. Exploiting unique alignment of cobalt-ferrite nanoparticles, mild hyperthermia, and controlled intrinsic cobalt toxicity for cancer therapy. Adv. Mater. 2020, 91, 017203. [CrossRef]

21. Sharrock, M.P. Recent advances in metal particulate recording media: Toward the ultimate particle. IEEE Trans. Magn. 2000, 36, 2420-2425. [CrossRef]

22. Goh, C.K.; Yuan, Z.M.; Liu, B. Magnetization reversal in enclosed composite pattern media structure. J. Appl. Phys. 2009, 105, 083920. [CrossRef]

23. De Toro, J.A.; Marques, D.P.; Muñiz, P.; Skumryev, V.; Sort, J.; Givord, D.; Nogués, J. High Temperature Magnetic Stabilization of Cobalt Nanoparticles by an Antiferromagnetic Proximity Effect. Phys. Rev. Lett. 2015, 115, 057201. [CrossRef] [PubMed]

24. Normile, P.S.; De Toro, J.A.; Muñoz, T.; González, J.A.; Andrés, J.P.; Muñiz, P.; Galindo, R.E.; Riveiro, J.M. Influence of spacer layer morphology on the exchange-bias properties of reactively sputtered Co/Ag multilayers. Phys. Rev. B 2007, 76, 104430. [CrossRef]

25. Berkowitz, A.E.; Takano, K. Exchange Anisoropy-a Review. J. Magn. Magn. Mater. 1999, 200, 552-570. [CrossRef]

26. Baltz, V.; Sort, J.; Rodmacq, B.; Dieny, B.; Landis, S. Thermal activation effects on the exchange bias in ferromagnetic- antiferromagnetic nanostructures. Phys. Rev. B Condens. Matter Mater. Phys. 2005, 72, 104419. [CrossRef]

27. Feygenson, M.; Yiu, Y.; Kou, A.; Kim, K.S.; Aronson, M.C. Controlling the exchange bias field in Co core/CoO shell nanoparticles. Phys. Rev. B Condens. Matter Mater. Phys. 2010, 81, 195445. [CrossRef]

28. Stiles, M.D.; McMichael, R.D. Coercivity in exchange-bias bilayers. Phys. Rev. B Condens. Matter Mater. Phys. 2001, 63, 064405. [CrossRef]

29. Nascimento, V.P.; Passamani, E.C.; Alvarenga, A.D.; Biondo, A.; Pelegrini, F.; Saitovitch, E.B. Bottom and top AF/FM interfaces of $\mathrm{NiFe} / \mathrm{FeMn} / \mathrm{NiFe}$ trilayers. Appl. Surf. Sci. 2008, 254, 2114-2119. [CrossRef]

30. Kovylina, M.; Del Muro, M.G.; Konstantinović, Z.; Varela, M.; Iglesias, O.; Labarta, A.; Batlle, X. Controlling exchange bias in Co-CoOx nanoparticles by oxygen content. Nanotechnology 2009, 20, 175702. [CrossRef]

31. Iglesias, Ò.; Labarta, A.; Batlle, X. Exchange Bias Phenomenology and Models of Core / Shell Nanoparticles. J. Nanosci. Nanotechnol. 2008, 8, 2761-2780. [CrossRef] [PubMed]

32. Das, S.; Patra, M.; Majumdar, S.; Giri, S. Exchange bias effect at the irregular interfaces between Co and CoO nanostructures. J. Alloys Compd. 2009, 488, 27-30. [CrossRef]

33. Tracy, J.B.; Weiss, D.N.; Dinega, D.P.; Bawendi, M.G. Exchange biasing and magnetic properties of partially and fully oxidized colloidal cobalt nanoparticles. Phys. Rev. B Condens. Matter Mater. Phys. 2005, 72, 064404. [CrossRef]

34. Tracy, J.B.; Bawendi, M.G. Defects in CoO in oxidized cobalt nanoparticles dominate exchange biasing and exhibit anomalous magnetic properties. Phys. Rev. B Condens. Matter Mater. Phys. 2006, 74, 184434. [CrossRef] 
35. Antón, R.L.; González, J.A.; Andrés, J.P.; Normile, P.S.; Canales-Vázquez, J.; Muñiz, P.; Riveiro, J.M.; De Toro, J.A. Exchange bias optimization by controlled oxidation of cobalt nanoparticle films prepared by sputter gas aggregation. Nanomaterials $2017,7,61$. [CrossRef]

36. Antón, R.L.; González, J.A.; Andrés, J.P.; Canales-Vázquez, J.; De Toro, J.A.; Riveiro, J.M. High-vacuum annealing reduction of $\mathrm{Co} / \mathrm{CoO}$ nanoparticles. Nanotechnology 2014, 25, 105702. [CrossRef]

37. Bhowmik, R.N.; Nagarajan, R.; Ranganathan, R. Magnetic enhancement in antiferromagnetic nanoparticle of $\mathrm{CoRh}_{2} \mathrm{O}_{4}$. Phys. Rev. B 2004, 69, 054430. [CrossRef]

38. Sundaresan, A.; Bhargavi, R.; Rangarajan, N.; Siddesh, U.; Rao, C.N.R. Ferromagnetism as a universal feature of nanoparticles of the otherwise nonmagnetic oxides. Phys. Rev. B 2006, 74, 161306. [CrossRef]

39. Kisan, B.; Kumar, J.; Saravanan, P.; Perumal, A. Defect induced ferromagnetism in NiO nanocrystals: Insight from experimental and DFT+U study. Physica B 2020, 593, 412319. [CrossRef]

40. Dutta, D.P.; Sharma, G.; Manna, P.K.; Tyagi, A.K.; Yusuf, S.M. Room temperature ferromagnetism in CoO nanoparticles obtained from sonochemically synthesized precursors. Nanotechnology 2008, 19, 245609. [CrossRef]

41. Roca, A.G.; Golosovsky, I.V.; Winkler, E.; López-Ortega, A.; Estrader, M.; Zysler, R.D.; Baró, M.D.; Nogués, J. Unravelling the Elusive Antiferromagnetic Order in Wurtzite and Zinc Blende CoO Polymorph Nanoparticles. Small 2018, 14, 1703963. [CrossRef]

42. Skumryev, V.; Stoyanov, S.; Zhang, Y.; Hadjipanayis, G.; Givord, D.; Nogués, J. Beating the superparamagnetic limit with exchange bias. Nature 2003, 423, 850-853. [CrossRef]

43. Morrish, A.H. The Physical Principles of Magnetism; IEEE Press Classic Reissue: Holmdel, NJ, USA, 2001 ; ISBN 9780470546581.

44. Zhu, H.T.; Luo, J.; Liang, J.K.; Rao, G.H.; Li, J.B.; Zhang, J.Y.; Du, Z.M. Synthesis and magnetic properties of antiferromagnetic Co3O4 nanoparticles. Physica B 2008, 403, 3141-3145. [CrossRef]

45. He, L.; Chen, C. Finite size effect on Néel temperature with $\mathrm{Co}_{3} \mathrm{O}_{4}$ nanoparticles. J. Appl. Phys. 2007, 102, 103911. [CrossRef]

46. Dobrynin, A.N.; Levlev, D.N.; Temst, K.; Lievens, P.; Margueritat, J. Critical size for exchange bias in ferromagneticantiferromagnetic particles. Appl. Phys. Lett. 2005, 87, 012501. [CrossRef]

47. Inderhees, S.E.; Borchers, J.A.; Green, K.S.; Kim, M.S.; Sun, K.; Strycker, G.L.; Aronson, M.C. Manipulating the Magnetic Structure of Co Core/CoO Shell Nanoparticles: Implications for Controlling the Exchange Bias. Phys. Rev. Lett. 2008, 101, 117202. [CrossRef]

48. You, B.; Wang, Y.; Zhao, Y.; Sun, L.; Sheng, W.; Pan, M.; Du, J.; Hu, A.; Lu, M. Exchange bias in Co/Co3O4 bilayers. J. Appl. Phys. 2003, 93, 6587-6589. [CrossRef]

49. Wang, Y.; Zhang, Y.; Cao, Y.; Lu, M.; Yang, J. Properties of exchange biased $\mathrm{Co} / \mathrm{Co}_{3} \mathrm{O}_{4}$ bilayer films. J. Alloys Compd. 2008, 450, 128-130. [CrossRef]

50. Mishra, S.R.; Dubenko, I.; Khan, M.; Young, T.; Ganegoda, H.; Ali, N.; Marasinghe, G.K. Exchange-Coupled FeNi-X (X = CuO, $\mathrm{NiO}$, and $\mathrm{CoO})$ Nanocomposites Prepared Via Ball Milling. IEEE Trans. Magn. 2006, 42, 2808-2811. [CrossRef]

51. Ohldag, H.; Scholl, A.; Nolting, F.; Arnholz, E.; Maat, S.; Young, A.T.; Carey, M.; Stöhr, J. Correlation between Exchange Bias and Pinned Interfacial Spins. Phys. Rev. Lett. 2003, 91, 17203. [CrossRef]

52. Fitzsimmons, M.R.; Kirby, B.J.; Roy, S.; Li, Z.; Roshchin, I.V.; Sinha, S.K.; Schuller, I.K. Pinned magnetization in the antiferromagnet and ferromagnet of an exchange bias system. Phys. Rev. B 2007, 75, 214412. [CrossRef] 